\title{
Heterogeneity in Linguistic Behavior While Maintaining Identity Among the Users of Different Dialects of the Brahui Language
}

\author{
Sehrish Rabbani ${ }^{1}$ \\ 1Lecturer, Mir Chakar Khan Rind University, Sibi. \\ Mehwish Malghani ${ }^{2}$ \\ 2Professor, Mir Chakar Khan Rind University, Sibi. \\ Mehwish Ali Khan ${ }^{3}$ \\ 3Lecturer, SBK Women's University, Quetta. \\ Fahmeeda Manzoor ${ }^{4}$ \\ 4Lecturer, Sardar Bahadur Khan University, Quetta.
}

DOI: https://doi.org/10.54781/abz.v13i1.213

KEYWORDS

Heterogeneity, Dialectology, Isogloss, Convention Depersonalize

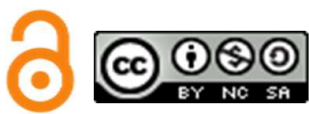

ABSTRACT

This study explores the lexical variation among Brahui dialects in general and, three main dialects of Brahui language Sarawani, Rakhshani, and Jalawani, in particular. The aim was to find out how far lexical variation marks the existence of identity and regional boundaries. The data was collected through interviews from 12 participants. In this study the social identity theory by Tajfel and Turner (1979) was used. The study reveals that lexical variety exists among the three Brahui dialects showing heterogeneity in the participants' linguistic behavior to keep up their identities which separates the inhabitant of one region from another region also showing the presence of regional boundaries.

Received: May 05, 2021; Accepted: October 08, 2021; Published: December 25, 2021

\section{Introduction}

Balochistan is an ethnically and linguistically diverse province. In this province, not only many languages are spoken, but also within one language there are many varieties. However, among these languages, Brahui is also spoken in many areas of Balochistan.

Brahui a Dravidian language basically spoken in Pakistan in the central part of Balochistan by the Brahui speakers and is also spoken in some parts of Turkmenistan, Afghanistan and Iran. This language is also spoken in Iraq, the United 
Arab Emirates, and Qatar by emigrant Brahui communities as well (Sabir,2002). Brahui is predominantly spoken in different areas of Balochistan such as in Khuzdar, Mastung, Noshki, and some parts of Quetta district.

The Brahui possess a reduced square of the nation around Kalat, for the most part, lying high and extending from Quetta in the north to Las Bela in the south, isolating Eastern Balochi locale from the Western Balochi.

(a) Kambarni, isolated into Ahmedzai (the ruling class of ex-Kalat State);

(b) Mirwani;

(c) Gurgnarhi;

(d) Sumalani;

(e) Kalandarani.

Other than the above clans, Zarakzais of Jalawan, the Raisanies of Sarawan, the Mengals of Naushki, and the greater part of the Rinds and Magassis of Kachi, speak Brahui. Hence, the Brahui speaking comprise of Kalat State including Sarawan and Jalawan, Kirthar-at the southern mouth of Mola Pass, Larkana District and different parts of Sindh in West Pakistan, and in Afghanistan around the Helmand Valley of Iran. As per the Census Report of 1961, the all-out Brahui talking population is 365,772 . However, this is particularly on the low side. Right off the bat, the statistics review in Balochistan was not sufficient, besides, the presence of bilingualism or rather multi-lingualism made trouble in the count, and opened the path for problems: lastly, no enumeration report is accessible of the Brahui-speaking population of Afghanistan and Iran (Bray, 1934).

About 4 million people speak Brahui languages, in Balochistan Province of Pakistan (Kausar \& Sarwar, 2015). UNESCO (2009) reported Brahui is one of the 27 endangered languages of Pakistan. The Classification is "unsafe", the less endangered position out of the 5 levels of limited (Unsafe, accurately Endangered, Severely Endangered, Critically Endangered, and Extinct) (Regan, Colyvan, \& Burgma, 2000).

Dialectology, as an efficient order, was the primary concern of the linguists in the second half of the nineteenth century. For the most part, dialectologists are worried about syntactic, lexical and phonological highlights that compare on regional premise. Each dialect has a number of vernaculars. Dialects are both local and social; Social dialect or sociolect can check the social class of the speaker. Thus, regional dialects can separate the occupant of one region from those of different regions (Wardhaugh, 2015). In this way, all speakers have a social and regional foundation (Chambers and Trudgill, 2004). Trudgill (2003) clarifies at whatever point a speaker talks he can't abstain from providing his audience some insight about his inception and his identity. For the most part, our pronunciations and discourse demonstrate where we are from geologically and what kind of social foundation we have.

This is one aspect that opens venues for research on this language. In addition, there are many dialects of Brahui language out of which Jalawan (center and south of Khuzdar) \& Sarawan ( center, North of Kalat) are the two well know. Generally, no important dialectal differences are assumed in different dialects but only that the dialects are separated by the pronunciation of $* h$, which is only available in the north. In this connection, the present research would investigate the heterogeneity in linguistic behavior in maintaining their identity Boundaries in Brahui Language in Balochistan.

\section{Literature Review}

Khan, Zaidi, and Rauf, (2017) investigated the negotiation among dialect and ethnicity by investigating the job of dialect as a segment and marker of ethnic identity in a linguistically different ethnic gathering, Baloch who talk somewhere around four distinct dialects which make one single ethnic individuals. The investigation explicitly asked if the dialect is the fundamental belief part of Baloch ethnicity. For this reason, one hundred and twenty-four youthful educated Baloch from various universities were purposively tested for unstructured interviews while observation was additionally utilized as a vital instrument for ethnography. The collected data were analyzed through the theoretical system of Smolicz Cultural Core Value Theory (1981). The examination of the gathered information appeared that the majority of the standard participants were monolinguals with one of the four dialects. Some were bilingual with Urdu, the most widely used language or with at least one dialects of the gathering. The investigation uncovers that whichever dialect the individuals from Baloch ethnic gathering communicate in, Balochi dialect holds an important place for them and it goes about as a solid ethnic identity marker and a 
guiding principle part of ethnicity for this linguistically assorted ethnic gathering (Khan, Zaidi, \& Rauf, 2007).

There are numerous authentic occasions, spots, identities, and establishments, which have assumed an amazing job for the improvement of countries on the planet. The place where there is Balochistan additionally has the same stories, occasions and above all a foundation, which changed the life and belief system of the general population. Maktaba-e-Durkhani is a renowned foundation and known for the gigantic administrations performed amid the British occupation in Balochistan. In 1839 the British assaulted and caught Balochistan for the satisfaction of her forward strategy and after the settlement of Mastung 1876, they had a total direction and all-out impact in the undertakings of Kalat. At that point, they concentrated on religion. The Britisher's plan was to advance Christianity in Brahui and Baloch talking territories so morally it was not reasonable for British experts to move such a development, which could specifically influence the religion of the general population. Baloch individuals were not able to raise their voices against such a demonstration since they had no school of thought and no such an initiative which could accumulate them against the British connivance. At the point when individuals were sad, the Maktaba-e-Durkhani assumed the liability and approached for the protection of Islam and drove the Baloch individuals towards anchored confidence. Maktaba-e-Durkhani satisfied its obligations by distributing various Books in Balochi and Brahui dialects and paid its administrations for appearing acceptable way to the general population of Balochistan. The accompanying examination work depends on the writing work and different administrations of this establishment (Raza, Baloch, \& Razzaq, 2017).

This research depicts the dialect variety of phonetic changes, discourse style, vocabulary changing and acquiring expressions of Brahui dialects. This article would attempt to demonstrate the reasons for variety in tongues of Brahui. One of the most compelling motivations with respect to colloquial variety is; the Brahui dialect is largely etymologically influenced by the neighboring dialects, similar to Balochi in Raxshani dialect, Urdu, English, and Pashto in Sarawani vernacular, Sindhi, Jathki, Last in Jalawani dialect. Towards the end a few suggestions are given for anticipating such colloquial changes in Brahui dialects. In the event that the lingual changes proceed with, it would be perilous for the Brahui dialect (Sani, Ahmed, \& Razzaq, 2014).

\section{Problem statement}

Balochistan is being home of ethnic groups and also has a vast linguistic repertoire with each ethnic group speaking a different language. The Brahui community has been living in different parts of Balochistan since ages. Brahui language has many dialects. The dialects are formed on the basis of regional boundaries. The areas where most of Brahui communities reside are Quetta, Kalat, Mastung, Khuzdar, Zehri, and Noshki. Their dialects consist of a variety of words which marks the difference between there dialect. The study brings to the forefront of the significance of their dialect in creating identities within the Brahui community. The study processes that identity formation tends to make one community feel superior to others.

\section{Significance of the study}

By highlighting the regional variations in the three major dialects of Brahui, the study benefits the Brahui community in general and Brahui language in particular as there is no evidence of similar research conducted in the existing literature. The study is also significant with regard to identity construction within the Brahui community, as it would focus on the convention of regional dialects with the identity formation that in one community.

\section{Theoretical Framework}

Social Identity Theory (SIT; Tajfel, 1978; Tajfel \& Turner, 1979) starts with the introduction that persons define their own particular characters as to identification work to ensure self-personality. Production of gathering characters includes both the arrangement of one's "out-gathering" "ingathering" concerning the inclination to view one's own particular gathering with a positive predisposition opposite the outgathering. The outcome is an identification with a group, depersonalized character in view of gathering participation and instilled with constructive viewpoints (e.g., Turner, 
Hogg, Oakes, Reicher, and Wetherell, 1987).

\section{Research Objective}

To investigate the heterogeneity in linguistic behavior in maintaining identity among the user of different dialects of Brahui.

\section{Research Question}

How heterogeneity as a linguistic behavior is used to maintain Brahui identity?

\section{Delimitation}

The study is delimited to 12 interviews for qualitative data analysis.

\section{Research Methodology}

The present research adopts Qualitative approach.

Qualitative data can be observed and recorded. This data type is non-numerical in nature. This type of data is collected through methods of observations, one-toone interviews, conducting focus groups, and similar methods. Qualitative data in statistics is also known as categorical data data that can be arranged categorically based on the attributes and properties of a thing or a phenomenon, in which researcher collect, analyze qualitative data in the study of inquiry to address their research question.

\section{Data Analysis}

In order to analyze qualitative data, the researcher has conducted semi-structured interviews to know heterogeneity linguistic behavior as used to maintain Brahui identity. The interviews have been analyzed through coding method. The researcher used the theoretical framework of Tajfel and Turner (1979) of social identity theory.

\section{Analysis of Interviews}

The method, which is used to analyze the interview data, is the thematic approach of Clark and Broun (2006). There is many other software to analyze the Qualitative data like (CAQDAS), NVIVO and ATLAS TI, but the researcher used Coding method of data analysis both automatically and manually. Following are the coding details of interviews.

\section{Question No 1.}

\section{Interviewer: Numa qaom ant e?}

(What is your cast?)

\begin{tabular}{|c||l|l|l||}
\hline $\begin{array}{l}\text { Interview } \\
\text { ee } \#\end{array}$ & Rakhshan & Sarawan & Jhalawan \\
\hline \hline 1 & Mengal & & \\
\hline 2 & Sasoli & & \\
\hline 3 & $\begin{array}{l}\text { Mohammad } \\
\text { Hasni }\end{array}$ & & \\
\hline 4 & Mengal & & \\
\hline 5 & & Sarparra & \\
\hline 6 & & Sarparra & \\
\hline 7 & & Mengal & \\
\hline 8 & & Sumalani & \\
\hline \hline 9 & & & Gurgnarhi \\
\hline \hline 10 & & & Jattak \\
\hline 11 & & & $\begin{array}{l}\text { Mohammad } \\
\text { Hasni }\end{array}$ \\
\hline 12 & & & Shahwani \\
\hline
\end{tabular}

\section{Analysis}

The researcher has interviewed 12 participants of three different dialects of Brahui language (Rakhshan, Sarawan and Jhalawan) who belong from different castes of Brahui language.

The first person, who was interviewed was from Rakhshani dialect and belonged to Mengal caste, the second person was from Sasoli caste, the third one was Mohammad Hasni by caste and the forth was from Mengal caste. The fifth interviewee was from Sarawani dialect who belongs to Sarparra caste, the sixth was again from Sarparra caste, the seventh one was from Mengal caste, and the eighth interviewee was from Sumalani cast. Moreover, the other four interviewees belonged from Jhalawani dialect, the ninth interviewee was from Gurgnarhi caste, the tenth one was from Jattak caste, eleventh was Mohammad Hasni by caste, and twelfth was from Shahwani caste. 


\section{Question No. 2}

Num Balochistan na ara jagaghaan taluk tikhere aur ara jagha ti rahengire?

(Which area of Balochistan do you belong to and reside in?)

\begin{tabular}{|c|c|c|c|}
\hline $\begin{array}{l}\text { Interv } \\
\text { iewee } \\
\#\end{array}$ & Rakhshan & Sarawan & Jhalawan \\
\hline 1 & $\begin{array}{l}\text { Noshki } \\
\text { Rakhshan }\end{array}$ & & \\
\hline 2 & $\begin{array}{l}\text { Noshki } \\
\text { Rakhshan }\end{array}$ & & \\
\hline 3 & $\begin{array}{l}\text { Noshki } \\
\text { Rakhshan }\end{array}$ & & \\
\hline 4 & $\begin{array}{l}\text { From Noshki } \\
\text { lives in } \\
\text { Quetta }\end{array}$ & & \\
\hline 5 & & $\begin{array}{l}\text { From } \\
\text { kardigap } \\
\text { lives in } \\
\text { Quetta }\end{array}$ & \\
\hline 6 & & Mastung & \\
\hline 7 & & Mastung & \\
\hline 8 & & $\begin{array}{lr}\text { From } & \text { Kalat } \\
\text { lives } & \text { in } \\
\text { Quetta } & \end{array}$ & \\
\hline 9 & & & Khuzdar \\
\hline 10 & & & Surab \\
\hline 11 & & & $\begin{array}{l}\text { From } \\
\text { Surab } \\
\text { lives in } \\
\text { Khuzdar }\end{array}$ \\
\hline 12 & & & Khuzdar \\
\hline
\end{tabular}

\section{Analysis}

The first person who was interviewed belongs to Rakhshani dialect and living in Noshki District.

The second interviewee who belongs to Noshki and living in Noshki District.

The third interviewee also belongs to Noshki and living in Noshki district.

The fourth interviewee belongs from Noshki but lives in Quetta.

The fifth interviewee was from Sarawani dialect who belongs from Kardigap but lives in Quetta district.

The sixth interviewee belongs from Mastung and lives in Mastung district.

The seventh one also belongs from Mastung and lives in Mastung district.

The eighth interviewee was from Kalat and lives in Quetta. The interviewees of
Jhalawani dialect the ninth interviewee belongs from Khuzdar and lives in Khuzdar district.

The tenth one belongs from Khuzdar and lives in Khuzdar.

The eleventh interviewee was from Surab and lives in Khuzdar.

And twelfth is from Khuzdar and lives in Khuzdar district. Most people are living in their basic birthplaces but some of them had shifted to new cities for betterment in their future and we also found that there are many interviewees who belong to same castes but living in different regions.

\section{Question No 3.}

Nume laggik ke Balochistan ati Rahengok inga Brahuik girha na girha as, asi warh at asi ailo an jita arer?

(Do you think Brahui people living in different areas of Balochistan are different from each other in any way?)

\begin{tabular}{|l|l||}
\hline \multirow{2}{*}{ Rakhshan 1 } & $\begin{array}{l}\text { Yes people living in Balochistan } \\
\text { are different by their look and } \\
\text { culture }\end{array}$ \\
\hline Rakhshan 2 & $\begin{array}{l}\text { Yes they are different by caste by } \\
\text { area }\end{array}$ \\
\hline Rakhshan 3 & $\begin{array}{l}\text { All Brahuis are same all are } \\
\text { Brahuis }\end{array}$ \\
\hline Rakhshan 4 & $\begin{array}{l}\text { There is a difference between } \\
\text { Brahui people }\end{array}$ \\
\hline \hline Sarawan 1 & $\begin{array}{l}\text { They are different by caste and } \\
\text { culture }\end{array}$ \\
\hline Sarawan 2 & No comments \\
\hline Sarawan 3 & $\begin{array}{l}\text { Specially their culture Tone and } \\
\text { Gestures way of talking are } \\
\text { different }\end{array}$ \\
\hline \hline Sarawan 4 & $\begin{array}{l}\text { Yes off course they are different } \\
\text { from each other }\end{array}$ \\
\hline \hline Jhalawan 1 & In some way Different \\
\hline \hline Jhalawan 2 & Yes there is Difference \\
\hline \hline Jhalawan 3 & Little bit difference \\
\hline \hline Jhalawan 4 & $\begin{array}{l}\text { Their Culture and castes are } \\
\text { Different }\end{array}$ \\
\hline \hline
\end{tabular}

\begin{tabular}{|l||l||l|}
\hline Yes & No & No comment \\
\hline \hline $75 \%$ & $17 \%$ & $8 \%$ \\
\hline
\end{tabular}




\section{Analysis}

This question is regarding variation among people who speak Brahui; actually, this question states that there is some difference between people who are living in Balochistan?

The first person who is from Rakhshan was interviewed said that "yes people who are living in Balochistan are different from each other by caste by culture exactly all people cannot belong to the same caste and culture cannot be same geographically, like Noshki has its own culture which is totally different from other regions like Khuzdar and Mastung.

The second person said that there is a difference by area by caste they are different from each other.

The answer of the third person is interesting and changed from other participants he says that all Brahui are same and there is no difference between them, his answer is an outlier and strange. Moreover, the fourth person said yes, there is a difference.

The first person from Sarawani dialect also said there is a difference between all of them. In addition, the second person from Sarawani dialect did not comment on this issue. The third person said off course there is a difference between them.

The first person from Jhalawani dialect said that not all Brahui speaking people are too much different from each other but in some cases, they are different.

The third person said that they are different from each other at a smaller level.

And the last person from Jhalawani dialect said that all Brahui speaking people are different from each other whether they are living in Rakhshan Sarawan or Jhalawan there is a way of lifestyle culture and Castes are different from each other.

Overall $75 \%$ of people said that Brahui speaking people are different from each other in many cases.

Like social identity theory the researcher also found that there are many differences between the groups.

Their caste their culture their lifestyle is different. They could not be called the same in any case.

Only $17 \%$ said that they are not different from each other.

\section{Question No 4.}

Nume laggik ke Balochistan ti Brahui lehja asi elo an jita o?

(Do you think Brahui dialects are different from each other?)

\begin{tabular}{||l|l||}
\hline \hline Rakhshan & $\begin{array}{l}\text { Yes all Brahui dialects in } \\
\text { Balochistan are different from one } \\
\text { another }\end{array}$ \\
\hline \hline $\begin{array}{l}\text { Rakhshan } \\
2\end{array}$ & $\begin{array}{l}\text { Yes all Brahui dialect in Balochistan } \\
\text { are different from one another }\end{array}$ \\
\hline \hline $\begin{array}{l}\text { Rakhshan } \\
3\end{array}$ & $\begin{array}{l}\text { There is a big difference among } \\
\text { Brahui dialects }\end{array}$ \\
\hline $\begin{array}{l}\text { Rakhshan } \\
4\end{array}$ & $\begin{array}{l}\text { There is a difference between } \\
\text { dialects }\end{array}$ \\
\hline Sarawan 1 & Yes there is a difference \\
\hline \hline Sarawan 2 & Yes there is a difference \\
\hline Sarawan 3 & Yes there is a difference \\
\hline \hline Sarawan 4 & Yes there is a difference \\
\hline \hline Jhalawan 1 & Accent difference dialect difference \\
\hline \hline Jhalawan 2 & Yes there is a difference \\
\hline \hline Jhalawan 3 & Not too Much Difference \\
\hline \hline & $\begin{array}{l}\text { Big Difference among Brahui } \\
\text { dialects } \\
\text { Jhalawan }\end{array}$ \\
\hline
\end{tabular}

\begin{tabular}{|c||c|}
\hline $\begin{array}{l}\text { Big difference among } \\
\text { Brahui dialects }\end{array}$ & Not a big difference \\
\hline \hline$(92 \%)$ & $(8 \%)$ \\
\hline
\end{tabular}

\section{Analysis}

The answers of all twelve interviewees revealed that there is a big difference between all three dialects (Sarawani, Rakhshani and Jhalawani) of Brahui language in Balochistan. The answers also revealed that $92 \%$ people think that there is a big difference in all three dialects of Brahui language and only $8 \%$ people think there is a small difference in these dialects of Brahui Language in Balochistan. This is clearly presented in the graph above.

The first person from Rakhshan region said that all Brahui dialects in Balochistan are different from each other he also gave a logic that at every 40 kilometers dialect changes, their language their culture their way of spending life also varies. The second person from Rakhshani dialect said that all Brahui speaking people are different from one another he said if a person talks in Khuzdar dialect we laugh at many words of them, though they are right according to 
standard of their language but their words are not acceptable for us and make us laugh on their words and tone of language. The third person from Rakhshani dialect also verified that there is a difference among these three major Brahui dialects, all of these are different from each other in some cases, not at all.

The fourth person also said that there is a difference among these dialects we are not familiar with other dialects of Brahui language like Sarawani and Jhalawani.

The first person from Sarawani dialect said that there is a difference between all Brahui dialects spoken in Balochistan. and the second person also said that there is a big difference between all Brahui dialects of Balochistan, the third person from Sarawani dialect also confirmed that there is a variation between dialects of Brahui languages of Balochistan all of them are different from one another. The fourth person from Sarawan said that all Brahui dialects are not the same there are some differences among them in their vocabulary and dialects.

The first person from Jhalawani dialect said that there is a difference between their accent and their culture also all people who are living in a region are not the same and especially if we look at Brahui speaking people, Rakhshani Brahui speaking people are totally changed from Brahui speaking people of Jhalawan, because Brahuis of Rakhshan are different by their accent is like Balochi Rakhshani.

There are two major Mengal groups in Balochistan one group is living in Waddh Khuzdar and Naal area another is living in Noshki region, though both are from one caste Mengal both are totally changed from each other. The second person from Jhalawan also confirmed the difference among these three main dialects of Balochistan Rakhshani, Jhalawani, and Sarawani.

The third person from Jhalawan said that there is no difference between all dialects of Brahui language, according to his opinion there is only one language of Brahui in Balochistan and all of them are same their way of speaking and tones are same. The fourth person said absolutely there is a big difference among them and not all Brahui dialects are the same. Thus, thorough the lenses of social identity theory people define their identity according to their social group.

\section{Question No 5:}

Interviewer: Acha num Kane girha as

anuno loaz paning kere arate num istemal kere aur o baki Brahui paroka ilaqa te ti istemal mafassa?

(Can you tell me some words that you use are different from the people living in other regions of Balochistan?)

\begin{tabular}{|c|c|}
\hline Codes & $\begin{array}{l}\text { Some Brahui words which are } \\
\text { different by area }\end{array}$ \\
\hline $\begin{array}{l}\text { Rakhshan } \\
1\end{array}$ & Noshki Zund, Mastung Toolh \\
\hline $\begin{array}{l}\text { Rakhshan } \\
2\end{array}$ & Zund Toolh \\
\hline $\begin{array}{l}\text { Rakhshan } \\
3\end{array}$ & $\begin{array}{l}\text { Mastung Dangi barak. Noshki } \\
\text { darhe barak }\end{array}$ \\
\hline $\begin{array}{l}\text { Rakhshan } \\
4\end{array}$ & Rahi Mohn, Garho Deg, \\
\hline Sarawan 1 & Toolh Zund, Narra Rum ka \\
\hline Sarawan 2 & Peshtammaa, Peshtingane \\
\hline Sarawan 3 & There is a difference \\
\hline Sarawan 4 & $\begin{array}{l}\text { Borhchikhana, } \\
\text { Balghurh Taata }\end{array}$ \\
\hline Jhalawan 1 & Chaaik Tiaaik \\
\hline Jhalawan 2 & Lohi and Garho \\
\hline Jhalawan 3 & $\begin{array}{l}\text { Lohi in Jhalawan and Deg } \\
\text { Mastung Sarawan }\end{array}$ \\
\hline Jhalawan 4 & Toolh Zund \\
\hline
\end{tabular}

\section{Analysis}

In the answer to the $5^{\text {th }}$ question, the researcher found so many words which were changed in all three dialects of Brahui language in Balochistan.

The first interviewee of Rakhshan dialect mentioned toolh and zund, he said in Noshki people use word zund to sit while in Sarawan people use toolh word for the same purpose, and said there are many other words which are not common between us the second interviewee mentioned the same difference in words toolh or zund. Where people from Rakhshan area use zund and people from Sarawani dialect use toolh for sitting purpose. The third interviewee of Rakhshan dialect told us that people from Sarawan say dangi barak for "to come here" but people of Rakhshani dialect say darhe 
barak which shows the graph phonic difference between dialects and also said there are many other words between us which are different from one another. The forth interviewee spoke briefly of two different words one was Rahi $k a$ that is spoken in Rakhshani dialect which means, "To send" and in Sarawani dialect people use mon ete or rahi karte.

The first interviewee of Sarawani dialect mentioned two words one was toolh, zund which was also mentioned by two interviewees of Rakhshan dialect previously and the second word was narra it is used in Sarawan and in Rakhshan people use rum $\mathrm{ka}$ which means "run" for the similar word nary. The second interviewee told us another sound level different word he said the people of Sarawan use peshtam, which means, "get out" while the people of Jhalawani dialect use instead of peshtam, Peshtingane, the third interviewee did not mention any word. While the fourth interviewee said two different words one was Borhchikhana which means "kitchen" which is spoken by the people of Sarawan and people of Jhalawan use word Dalaan for kitchen and she further said people of Jhalawan use word Balghurh for "Mother in law" but people of Rakhshani dialect use word Taata for same purpose.

The first interviewee from Jhalawani dialect mentioned the word Chaaik and Tiaaik, he said the people of Sarawan and Jhalawan use word Chaaik which means, "To know" while people of Rakhshan use word Tiaaik instead of Chaaik. The second interviewee mentioned Lohi and Garho people from Jhalawani dialect use loi and the people of Rakhshani dialect use the word Garho for "cooking or cooking pan". The third interviewee told us that people of Jhalawan use Lohi but in Sarawan people use word deg, so, the second and third interviewees of Jhalawani dialect mentioned three different words for "cooking or cooking pan" in three different dialects of Brahui language. Moreover, the fourth interviewee again mentioned the word toolh and zund. Therefore, in conclusion, it is clear that many vocabularies among these geographic areas are different from each other. There is a difference among these three main dialects of Balochistan. Therefore, through the lens of social identity theory people through their language identify their group or their dialect.

\section{Question No 6:}

Interviewer: Nume antae laggik numa qaom na bandagh aak pen ilaqa ti rehengira ofta zuban numa warh e ya nume an jita $e$ ?

(Do people of your cast use the same dialect all over Balochistan or dialects vary due to the region they reside in?)

\begin{tabular}{|c|c|}
\hline $\begin{array}{l}\text { Rakhshan } \\
1\end{array}$ & Speak same language \\
\hline $\begin{array}{l}\text { Rakhshan } \\
2\end{array}$ & No their language is change \\
\hline $\begin{array}{l}\text { Rakhshan } \\
3\end{array}$ & No their language is change \\
\hline $\begin{array}{l}\text { Rakhshan } \\
4\end{array}$ & Their language is change \\
\hline Sarawan 1 & Their language is change \\
\hline Sarawan 2 & Their language is change \\
\hline Sarawan 3 & $\begin{array}{l}\text { There is a difference between } \\
\text { languages }\end{array}$ \\
\hline Sarawan 4 & Speak our language \\
\hline $\begin{array}{l}\text { Jhalawan } \\
1\end{array}$ & Speak according to region \\
\hline $\begin{array}{l}\text { Jhalawan } \\
2\end{array}$ & Their language is change \\
\hline $\begin{array}{l}\text { Jhalawan } \\
3\end{array}$ & Their language is change \\
\hline $\begin{array}{l}\text { Jhalawan } \\
4\end{array}$ & Their language is change \\
\hline
\end{tabular}

\section{Analysis}

When the interviewer questioned either people of their caste used the same dialect all over Balochistan or the dialects varied to the regions they resided?

The first interviewees of Rakhshani dialect answered that the people of our caste speak the same dialect all over Balochistan, if they go to any other region or country they prefer to talk in their own native language but this answer is somewhat strange for example in Dubai or England how they can use their own language for communication. While the other three interviewees of Rakhshani dialect said that no their language changes according to their regions where they reside. Because they think their relatives who belong from their own caste but living in other regions are not talking in the same dialect, their language is affected by the circumstance of their residing area. 
The first three interviewees of Sarawani dialect said that they do not speak own dialect, their dialect is changing according to their regions but the fourth interviewee answered that the people of their caste speak the same dialect no matter where they reside. On the other hand, all four interviewees of Jhalawani dialect said that the people who belong to the same castes but reside in different regions of Balochistan their dialect would be changed according to the region.

However, $83 \%$ people think their dialect would change according to the region while only $17 \%$ people think that the people of same caste speak same dialect, their dialect would not change according to the region. That is clearly presented in the map below.

\begin{tabular}{|c||c||}
\hline $\begin{array}{l}\text { Speak the same } \\
\text { language }\end{array}$ & $\begin{array}{l}\text { Their language is } \\
\text { change }\end{array}$ \\
\hline \hline $17 \%$ & $83 \%$ \\
\hline
\end{tabular}

\section{Question No 7:}

Interviewer: nume ant laggik Balochistan na ara Brahui dialect kul an Juan e?

(Which dialect is superior among the Brahui dialects used in Balochistan?)

\begin{tabular}{|l||c||}
\hline $\begin{array}{l}\text { Rakhshan } \\
1\end{array}$ & Sarawan \\
\hline $\begin{array}{l}\text { Rakhshan } \\
2\end{array}$ & Khuzdari is original \\
\hline $\begin{array}{l}\text { Rakhshan } \\
3\end{array}$ & Jhalawan is Superior \\
\hline $\begin{array}{l}\text { Rakhshan } \\
4\end{array}$ & $\begin{array}{l}\text { Everyone thinks his Brahui is } \\
\text { better }\end{array}$ \\
\hline \hline Sarawan 1 & Mastung Brahui is the best \\
\hline \hline Sarawan 2 & Sarawan Brahui is the best \\
\hline \hline Sarawan 3 & Sarawan Brahui is the best \\
\hline \hline Sarawan 4 & Jhalawan is Superior \\
\hline \hline Jhalawan 1 & Jhalawan Brahui is the best \\
\hline \hline Jhalawan 2 & No Comments \\
\hline \hline Jhalawan 3 & Jhalawani is my favorite \\
\hline \hline Jhalawan 4 & Sarawani Brahui is the best \\
\hline \hline
\end{tabular}

\begin{tabular}{|l|l|l|l||}
\hline Jhalawan & Sarawan & Rakhshan & $\begin{array}{l}\text { No } \\
\text { comments }\end{array}$ \\
\hline $\mathbf{( 3 3 \% )}$ & $\mathbf{( 5 0 \% )}$ & $\mathbf{( 0 \% )}$ & $\mathbf{( 1 7 \% )}$ \\
\hline
\end{tabular}

\section{Analysis}

Majority of the participants think Sarawani dialect is superior because mostly literature and writings are in Sarawani dialect and mostly writers belong to this dialect. but according to some interviewees, Jhalawani dialect is superior, because they said, the real Brahui language of Balochistan comes from Khuzdar region and it is pure and not affected by other languages. It is clearly mentioned in the above graph that $50 \%$ people think Sarawani dialect is superior, according to $33 \%$ people, Jhalawani dialect is superior, and $17 \%$ people did not comment on this question. So, it is clearly mentioned that most people think that Sarawani dialect is superior because mostly literature and writings are in this dialect.

\section{Question No 8:}

Antae nume laggik $k$ da lehja kul an Juan e? (Why do you think this particular dialect is superior?)

\begin{tabular}{|c|c|}
\hline $\begin{array}{l}\text { Rakhshan } \\
1\end{array}$ & $\begin{array}{l}\text { Mostly literature is in } \\
\text { Sarawani Dialects }\end{array}$ \\
\hline $\begin{array}{l}\text { Rakhshan } \\
2\end{array}$ & $\begin{array}{l}\text { Because dialect of Jhalawan } \\
\text { is pure }\end{array}$ \\
\hline $\begin{array}{l}\text { Rakhshan } \\
3\end{array}$ & $\begin{array}{l}\text { Because not affected by other } \\
\text { languages }\end{array}$ \\
\hline $\begin{array}{l}\text { Rakhshan } \\
4\end{array}$ & $\begin{array}{l}\text { Everyone likes his own } \\
\text { dialect }\end{array}$ \\
\hline Sarawan 1 & $\begin{array}{l}\text { Mastung Brahui is the best, } \\
\text { and we like to communicate } \\
\text { in it }\end{array}$ \\
\hline Sarawan 2 & $\begin{array}{l}\text { Because our literature is in } \\
\text { Sarawani dialect }\end{array}$ \\
\hline Sarawan 3 & Because it is our identity \\
\hline Sarawan 4 & Because it is pure \\
\hline Jhalawan 1 & $\begin{array}{l}\text { Because it is pure and not } \\
\text { affected }\end{array}$ \\
\hline Jhalawan 2 & No comments \\
\hline Jhalawan 3 & It is pure \\
\hline Jhalawan 4 & $\begin{array}{l}\text { Literature is written in } \\
\text { Sarawani dialect }\end{array}$ \\
\hline
\end{tabular}

\begin{tabular}{|l|l||l|l||}
\hline Jhalawan & Sarawan & Rakhshan & $\begin{array}{l}\text { No } \\
\text { Comments }\end{array}$ \\
\hline \hline $\mathbf{( 3 3 \% )}$ & $\mathbf{( 5 0 \% )}$ & $\mathbf{( 0 \% )}$ & $\mathbf{( 1 7 \% )}$ \\
\hline
\end{tabular}




\section{Analysis}

The $50 \%$ interviewees said that most literature is in Sarawani dialects, if we analyze their statements, their statements are somehow true because major literature is in Sarawani dialect or the majority of writers belong to Sarawan. 33\% of interviewees said that Jhalawani dialect is pure or original; they think that Jhalawani is the orientation of Brahui language and firstly Brahui was started from mountainous areas of Jhalawan. In addition, $17 \%$ did not respond on this question. Therefore, it is clearly mentioned in the chart that majority of the interviewees think that the presence of literature in Sarawani dialect makes it superior.

\section{Question No 9:}

Num pen jagha as hampire to num tena zuban a kere ya ofta zuban e arfire?

(Do you change your dialect in case you move to another region of Balochistan?)

\begin{tabular}{|l||l||}
\hline $\begin{array}{l}\text { Rakhshan } \\
1\end{array}$ & We will continue our own dialect \\
\hline \hline $\begin{array}{l}\text { Rakhshan } \\
2\end{array}$ & I will continue my own Brahui \\
\hline $\begin{array}{l}\text { Rakhshan } \\
3\end{array}$ & $\begin{array}{l}\text { We will adopt the new language } \\
\text { according to that area }\end{array}$ \\
\hline $\begin{array}{l}\text { Rakhshan } \\
4\end{array}$ & The new one \\
\hline \hline Sarawan 1 & The old one \\
\hline \hline Sarawan 2 & Continue our own dialect \\
\hline \hline Sarawan 3 & Continue our own dialect \\
\hline \hline Sarawan 4 & Continue our own dialect \\
\hline \hline Jhalawan 1 & Adopt new one \\
\hline \hline Jhalawan 2 & Continue our own dialect \\
\hline \hline Jhalawan 3 & Continue our own dialect \\
\hline \hline Jhalawan 4 & Continue our own dialect \\
\hline
\end{tabular}

\begin{tabular}{|c||c|}
\hline $\begin{array}{l}\text { Continue our own } \\
\text { dialect }\end{array}$ & $\begin{array}{l}\text { Adopt new Brahui } \\
\text { language }\end{array}$ \\
\hline \hline$(75 \%)$ & $(25 \%)$ \\
\hline
\end{tabular}

\section{Analysis}

According to social identity theory people would maintain their identity through their language and that help them in creation of their group.

That is clearly mentioned in the above graph that $75 \%$ people would continue with their own dialect, they would not change their dialect while moving to another region of Balochistan and only $25 \%$ people would adopt the new dialect according to that area. So from this questions.

We concluded that most people want to continue their own language in case of shifting to another region because they think that the only thing which is their own identity in the new society is their language, not their name. They feel pride in using their own dialect, their own language in a foreign country or in a new place. One of the best examples is Pakistani community in UK Birmingham where many Pakistanis are living from decades though they are mostly using English as a language to communicate with the local and other people they are not unaware of their own language, they are using their national language Urdu at home.

\section{Question No 10:}

Ant a ki gurha num tena zuban e kere ya antae kappere ta? (Why you people would change your dialect if not then why?)

\begin{tabular}{|c|c|}
\hline $\begin{array}{l}\text { Rakhshan } \\
1\end{array}$ & Because I love my dialect \\
\hline $\begin{array}{l}\text { Rakhshan } \\
2\end{array}$ & It is easy for me \\
\hline $\begin{array}{l}\text { Rakhshan } \\
3\end{array}$ & $\begin{array}{l}\text { According to the environment } \\
\text { we will use a new one }\end{array}$ \\
\hline $\begin{array}{l}\text { Rakhshan } \\
4\end{array}$ & $\begin{array}{l}\text { That will be easy to } \\
\text { communicate }\end{array}$ \\
\hline Sarawan 1 & $\begin{array}{l}\text { Own dialect comes from our } \\
\text { forefathers }\end{array}$ \\
\hline Sarawan 2 & It is easy for me \\
\hline Sarawan 3 & $\begin{array}{l}\text { We are more familiar with } \\
\text { our Brahui }\end{array}$ \\
\hline Sarawan 4 & $\begin{array}{l}\text { Because their dialect or } \\
\text { language is difficult }\end{array}$ \\
\hline Jhalawan 1 & $\begin{array}{l}\text { Because it will be beneficial } \\
\text { in a new place }\end{array}$ \\
\hline Jhalawan 2 & I like my Brahui \\
\hline Jhalawan 3 & $\begin{array}{l}\text { It is our basic language and it } \\
\text { can't be changed }\end{array}$ \\
\hline Jhalawan 4 & I like my Brahui \\
\hline
\end{tabular}




\section{Analysis}

The first person who was interviewed was from Rakhshan and he said that if he would shift to another place he would prefer to use his own native language to communicate because he likes his language as compared with other dialects. The second person was also from Rakhshan according to him his own dialect is easy for him and he prefers his own way of communication in any region.

The third person gave an answer that he would use any dialect according to the situation because their dialect is only useful in their homeland but in other regions, their language will not be capable to communicate in fluently, so they can use the new language according to the situation. The Fourth person from Rakhshan said that new language would be easy to use because in the new region the majority of the people would have changed dialect so we would adopt the dialect of the majority.

The first person from Sarawani dialect said that they would use their own language because this language came to them from their ancestors and it is impossible for them to leave their native dialect so that they could use their own dialect.

The second person from Sarawan said that he would use his own dialect if he shifted to new area geographically because his own language would be easier for him.

The third person from Sarawan said that he would use his own language because his own way of speaking his own dialect is easier for him and he is more familiar with his native dialect. Also, the person interviewed on number four, from Sarawan said that he would use his own dialect, which is easy for him to communicate.

The answer of the first person from Jhalawani dialect is very interesting he thinks that the new dialect will be beneficial for him because in the new region the only language is the best tool to get them closer to the society by which society will easily accept them.

The second person from Jhalawan said that he likes his own Brahui in the new region because the new language will be difficult for him.

The third person said that their own language is fixed and it cannot be changed, if they shifted to other Brahui region obviously, they would use their own dialect. Moreover.

The last person from Jhalawan said that he likes his own language to communicate. Therefore, in conclusion, most people say that they will use their own language in the new region because it will be comfortable and easy for them to communicate. So, through the lens of Social Identity Theory (SIT; Tajfel, 1978; Tajfel \& Turner, 1979) individuals define their own identities with regard to social groups and that such identifications work to protect self-identity.

\section{Findings}

Henri Tajfel recommended that stereotyping (for example placing individuals into gatherings and classifications) depend on an ordinary subjective procedure: the propensity to aggregate things. In doing as such we will, in general, overstate,

1. the contrasts between gatherings.

2. the similitudes of things in a similar gathering. Likewise, these tables demonstrate the aftereffects of the lexical variety among three Brahui dialects Sarawani, Rakhshani and Jhalawani in three different regions. These outcomes have been acquired from the information and from the perception of the semantic conduct of the Brahui speakers of Mastung, Noshki, and Khuzdar or Zehri, Kalat, etc. The examination of these twenty Brahui variants recommends that lexical variety happens between three Brahui dialects. By seeing present occurrences of lexical variety, it tends to be seen that individuals from various regions utilize explicit variations in explicit areas to keep up their identity.

By examining these variations, it very well may be caught that identity and dialect are interlinked. The nearness or nonappearance of these particular variations in three Brahui dialects drives us to state that the region assumes an imperative job in lexical variation. Chambers and Trudgill (2004) state in this situation on the off chance that we head out from spot to put we find phonetic contrasts through which we can separate one town from another town. These distinctions may be bigger or littler. Ward-augh and Fuller (2015) additionally bring up that regional dialect separates the inhabitants of one region from different regions.

These outcomes likewise propose that lexical variety not exclusively can be seen in word level however similarly in the sound level occupants of these particular areas. The high rate demonstrates that respondents of different regions for maintaining their identity while going to 
another region they will not change their dialect according to the region to cognizant about their phonetic conduct.

The tables revile that there are many variations in Brahui variants as word-level variation and sound or graph-phonic level variations. Henri Tajfel and Jhon Turner (1979) state that “part of a person' concepts of self-come from the groups to which that person belongs".

However, the respondents showed variation in their linguistic behavior according to their groups through these tables. It also explored lexical variations that differentiate the people of one region from another region to mark the existence of regional boundaries with special reference to Brahui language. The factual investigation of the information yields the outcome that the relationship between the linguistic variable and social variable is significant.

Our qualitative data leads us to the answer to our second question. The heterogeneity in linguistic behavior is used for maintaining identity among the user of different dialects of Brahui. Tajfel and Turner's social identity theory explains that part of a person's concept of self comes from the groups to which that person belongs. An individual does not just have personal selfhood, but multiple selves and identities associated with their affiliated groups.

A person might act differently in varying social contexts according to the groups they belong to, which might include a sports team they follow, their family, their country of nationality, and the neighborhood they live in, among many other possibilities. (Turner \& Tajfel 1986).

The results revile that the respondents of different dialects would not change their dialects while going to another region for maintaining their identity. The researcher also finds out that those dialects are considered superior in which most of Brahui literature is written and dialects of rural areas, which are not damaged by other languages.

Our investigation allowed us to conclude that various variations are in charge of linguistic variety.

Phonetic variety collaborates with a regional alliance, sexual orientation and instruction. Every one of these components makes up the person's identity. As Wardaugh (2011) says people are not the same in their phonetic capacities. Individuals are unique in relation to each other by their sexual orientation, religion, age instruction and ethnicity.

Lexical variety among dialects is strengthened by local, social, political, racial contrasts. Therefore, we should along these lines presume that through lexical variety we could separate the occupant of one region from different districts. Hence based on this lexical variety we can propose territorial limits between three explicit regions of Balochistan Pakistan.

\section{Conclusion}

Sociolinguistic examinations have just talked about that how language changes starting with one area then onto the next and even individual to individual, the principal concern of this examination is to look at lexical variety among three Brahui dialects, for example, Sarawani, Rakhshani, and Jhalawani in Pakistani Balochistan.

The discoveries of this investigation lead us to find fascinating things concerning these three Brahui dialects.

The outcomes show that linguistic factors are engaged with lexical variety among Brahui dialects. Respondents from various dialects are heterogeneous in their phonetic practices.

Numerous elements are engaged with making up the individuals' identity, for example, region, sexual orientation, education, social and political background and ethnicity.

Individuals from various dialects utilize distinct variations from each other. In addition, respondents from different regions prefer to use their own dialect while going to another region in order to maintain identity among the user of different dialects of Brahui.

Most respondents' think that those dialects are superior, in which the literature of language is written and those dialects, which speak in rural areas.

So we can finish up in Pakistani Balochistan people from various regions utilize diverse linguistic structures in their everyday schedule discussion. They receive explicit linguistic behavior just to keep up their identity.

In this manner, we can draw territorial limits between various regions of Pakistani Balochistan based on lexical variety among Brahui dialects. 


\section{References}

Chambers, J. K. \& Trudgill, P. (2004). Dialectology.2nd edition. Cambridge: Cambridge University Press.

Kausar, \& Sarwar, M. (2015). The History of the Urdu Language Together with Its Origin and Geographic Distribution.

Khan, F. R., Zaidi, N., \& Rauf, S. The Relationship Between Language and Ethnicity among Baloch people.

Raza, K., Baloch, M., \& Razzaq, W. (2017). Maktaba-e-Durkhani its Publication and Contribution in Social Awareness. Balochistan.

Regan, H. M., Colyvan, M., \& Burgman, M. A. (2000). A proposal for fuzzy International Union for the Conservation of Nature (IUCN) categories and criteria. Biological Conservation, 92(1), 101-108
Sabir, A.R. (2002)_International Journal of Dravidian Linguistics, Volumes 3637 department of linguistics, University of Kerala.

Sani, L. A., Ahmed, B., \& Razzaq, W. (2014) Dialectal Variation of Brahui Language in Balochistan Language \& Literature. Balochistan.

Tajfel, H., \& Turner, J. C. (1979). An integrative theory of intergroup conflict. The social psychology of intergroup relations, 33(47), 74.

Wardaugh, R., \& Fuller, J. M. (2015). An Introduction to Sociolinguistic, $7^{\text {th }}$ edition. John Walley \& Sons. Inc Blackwell. 